\title{
Lifestyle counselling and behavioural change: role among adult hypertensives in a rural tertiary institution
}

\author{
AO Ayodapo ${ }^{\text {a* }}$ and TAV Olukokun ${ }^{b}$ \\ ${ }^{a}$ Department of Family Medicine, Federal Medical Centre, Birnin-Kebbi, Nigeria \\ ${ }^{b}$ Department of Family Medicine, Federal Medical Centre, Ido-Ekiti, Nigeria \\ *Corresponding author, email: aayodapo@gmail.com
}

Background: In spite of the availability of myriads of antihypertensive medications, the control of high blood pressure is still low. Studies on effect of lifestyle behavioural changes through counselling on blood pressure control are scant in Nigeria. Therefore, this study set out to determine the role of lifestyle counselling on behavioural change among hypertensive patients attending the Federal Medical Centre, Ido-Ekiti.

Methods: A total of 322 adult hypertensive participants who had been on treatment for at least three consecutive months were randomised into two groups. Relevant data were collected using an interviewer-administered semi-structured questionnaire and clinical parameters were measured pre- and post-intervention. The intervention group was counselled on lifestyle behaviours, namely regular exercise, eating adequate fruits and vegetables, moderate alcohol intake and cessation of smoking. Results: Post-intervention, among the intervention group $22.4 \%, 71.4 \%$ and $100 \%$, as compared with the control group at $6.2 \%$, $41.0 \%$ and $87.6 \%$, met recommendations for physical activity, fruit and vegetable consumption and alcohol consumption respectively. The difference in each category was statistically significant $(p<0.001)$. However, the difference in smoking habits between the two groups $(83.9 \%$ vs. $79.5 \%)$ was not statistically significant $(p=0.313)$. There was a statistically significant difference $(p \leq 0.001)$ in the difference in mean arterial pressure $(96.4 \pm 8.1 \mathrm{vs} 106.2 \pm 7.6 \mathrm{mmHg})$ between the intervention and control group post-intervention.

Conclusion: Lifestyle modifications form part of an important and effective treatment modality for hypertension. It is desirable that primary care physicians devise and implement clinical and public health strategies that promote and maintain a combination of pharmacologic interventions and lifestyle modifications.

\section{Introduction}

Hypertension is the leading risk factor for cardiovascular disease, affecting over $25 \%$ of the world population. ${ }^{1}$ Hypertension, the topmost risk factor for death worldwide, remains the commonest non-communicable disease in Nigeria and a leading cause of myocardial infarction, heart failure and stroke worldwide. ${ }^{2,3}$

The Seventh Report of the Joint National Committee on Prevention, Detection, Evaluation, and Treatment of High Blood Pressure (JNC-7) and the Nigerian Hypertension Society (NHS) guideline for the management of hypertension recommends lifestyle modification for all patients with hypertension or prehypertension. ${ }^{4}$ Adoption of a healthy lifestyle by all individuals is critical for the prevention of high blood pressure and is an indispensable part of the management of those with hypertension because, apart from contributing to the control of hypertension, these strategies are beneficial in managing most of the other cardiovascular risk factors. ${ }^{5,6}$ In hypertensive individuals with medication-controlled blood pressure, lifestyle modification may facilitate drug step-down and drug withdrawal in highly motivated individuals who achieve and maintain lifestyle changes, while in the non-hypertensive, lifestyle modification has the potential to prevent hypertension and, more broadly, to reduce blood pressure and thus lower the risk of blood pressure-related clinical complications in general populations. ${ }^{7}$ Although high degree of motivation is needed to sustain the benefits of non-pharmacological treatment, unfortunately data from a cross-sectional study showed that non-pharmacological treatment for patients with hypertension is still inadequate. ${ }^{8}$ Lifestyle modifications involve weight reduction, regular physical exercise, reduction of salt intake, healthy eating (diet rich in fruits, vegetables and dairy products with reduced saturated and total fat), restriction of alcohol intake and cessation of smoking, among others.

Studies of hypertension are frequently focused on only the pharmacological interventions; however, lifestyle behavioural changes are a cornerstone to the management of hypertension. Also, studies on the effect of nutritional and lifestyle behavioural changes counselling on blood pressure control are scant in Nigeria. Concern about the modifiable cardiovascular risk factors that are amenable to lifestyle behavioural changes prompted this present study.

\section{Materials and methods}

\section{Study area}

The study was conducted in the General Outpatient unit of the Family Medicine department at the Federal Medical Centre, Ido-Ekiti, Ekiti State. Although the hospital is a tertiary health institution, it also renders primary and secondary health care for a large number of people in its catchment areas of Ekiti, Kwara, Kogi, Ondo and Osun States. It is an accredited centre for postgraduate medical training in eight fields of medical and surgical specialties. The hypertensive patients are seen daily in the general outpatient department of the hospital by the resident doctors under the supervision of consultant family physicians.

\section{Study design}

The study was a hospital-based interventional study. 


\section{Duration of study}

The study was conducted over a period of 20 weeks.

\section{Sample size}

This was determined using the formula $n^{\prime}=2 z^{2} p q / d^{2}$. The minimum sample size was 141 . However, to allow for unexpected data losses and dropouts during recruitment, a sample size of 161 per group was used for the study.

\section{Sampling technique}

Simple random and systematic random sampling techniques were used to recruit subjects among hypertensive patients attending the clinic. The first participant was selected by simple random sampling; two small pieces of paper were marked YES and NO. The first two patients in the waiting area who gave consent to participate in the study were asked to pick one piece of paper, and the patient that picked the YES was the first for that day and then every second patient was selected by systematic random sampling. This was repeated every clinic day until the sample size was met.

\section{Randomisation of the study}

Subjects were allocated into two groups (control and intervention) by randomisation. The intervention and control group were randomised by using opaque envelopes numbered serially with cards that indicated whether a patient should be in the intervention or control group. They were matched for sociodemographic characteristics.

\section{Inclusion and exclusion criteria}

Inclusion criteria included hypertensive patients aged $\geq 30$ years and $\leq 80$ years, who had been on treatment for at least three consecutive months.

Excluded from the study were critically ill and psychiatric patients, and pregnant women.

\section{Ethical clearance and consent}

Ethical clearance was obtained from the Ethical Review and Research committee of the Federal Medical Centre, Ido-Ekiti. Informed verbal and written consent were also obtained from willing participants.

\section{Data collection and instruments}

A pre-tested semi-structured interviewer-administered questionnaire adapted from the World Health Organization (WHO) STEPS questionnaire was used, ${ }^{10}$ drafted in English.

The questionnaire was divided into three sections, namely: sociodemographic (section A), clinical data (section B) and lifestyle behaviour assessment (section C).

The hypertension-related lifestyle behaviours examined in this study were:

1. physical activity status;

2. fruit and vegetable consumption;

3. smoking status;

4. alcohol consumption.

Physical activity was assessed by asking participants how often and duration per session in a usual week and how long in their lifetime they engaged in moderate physical activities (such as brisk walking, bicycling, gardening or anything else that causes small increases in breathing or heart rate) or vigorous physical activities (such as running, weight training, organised sports or anything else that causes large increases in breathing or heart rate). Participants were then categorised as either met recommendations for physical activity (performing moderate physical activities for $\geq 30$ minutes per day on $\geq 5$ days per week and/or vigorous physical activities for $\geq$ 20 minutes per day on $\geq 3$ days per week) or did not meet physical activity recommendations (insufficient quantity to achieve either moderate or vigorous physical activity recommendations). ${ }^{11}$

Fruit and vegetable consumption was assessed by asking participants how many times per day they ate fruit/vegetables, how many servings and for how long. Participants were categorised as met recommendations if he/she consumed $\geq 5$ servings of fruits and vegetables per day and did not meet recommendations if he/she consumed $<5$ servings of fruits and vegetables per day. ${ }^{11}$ One serving of fruit was defined as an equivalent of one fruit (e.g. orange, mango) or one milk tin chopped size of fruit (e.g. pawpaw, pineapple), while one serving of vegetable was defined as an equivalent of three heaped tablespoons of vegetables (raw or cooked). ${ }^{12}$

Alcohol consumption was assessed by asking participants how many drinks of any alcoholic beverages they drank per week and for how long (a drink of alcohol was defined as an equivalent of one shot of liquor or one bottle of beer. One unit of drink contains 8 grams of alcohol). Participants were categorised as met recommendations if consuming moderate or no alcohol, taking $\leq 2$ drinks per day in men, and $\leq 1$ drink per day in women and did not meet recommendations if consuming $\geq 2$ drinks per day in men, and $\geq 1$ drink per day in women. ${ }^{5}$

Smoking status was assessed by asking participants how many cigarettes they smoked per day and for how long, as well as how long have they been using snuff and/or chewing tobacco and how often. Participants were categorised as met recommendations if not smoking or stopped smoking and did not meet recommendations if smoking or chewing tobacco or using snuff. $^{13}$

Participants were assisted in various ways. Analgesics were prescribed for some participants who complained of body pains following uptake of regular physical activity. The obese/overweight participants were advised to enrol at a gymnasium where they could join a support group to take regular exercise. Participants who were drinking alcohol (who did not meet the recommendation) or smoking were advised to write a change plan, obtain a substitute for alcohol/smoking and enlist the help of their spouse(s) in stopping the habit(s). Some participants drinking alcohol or smoking were linked to community resources (religious body) and advised to spend their leisure time on religious activities to assist them in stopping the habit(s).

An Accoson ${ }^{\circledast}$ brand (Accoson, Harlow, Essex, UK) mercury sphygmomanometer with appropriate cuff and stethoscope was used to measure the blood pressure of the patients in a sitting position using the left arm. An appropriate-sized cuff with bladder encircling at least $80 \%$ of the arm was used. The first appearance of sound (phase 1 Korotkoff) was used for systolic blood pressure (SBP), and a phase 5 Korotkoff sound (disappearance of sound) was used to measure diastolic blood pressure (DBP). The blood pressure was recorded to the nearest $2 \mathrm{mmHg}$. Two measurements were taken after the 
patient has been allowed to sit for 5-10 minutes and an average value was taken. Mean arterial pressure (MAP) was calculated from the SBP and DBP.

\section{Research protocol}

The study was done in two phases. Phase 1 was the first contact with the patient when the sociodemographic data and clinical parameters such as blood pressure were taken, and the (baseline) questionnaire was administered to assess lifestyle behaviour for both the control and intervention groups. Counselling on lifestyle behaviours such as regular exercise, eating of adequate fruits and vegetables, moderate alcohol intake and stoppage of smoking was undertaken using the 'Five As' (ask, assess, advise, assist, arrange) technique ${ }^{14}$ for the intervention group by the principal investigator. Each counselling session for each participant lasted about 30-45 minutes. Each session started with open-ended interrogative communication using lay language. The author provided clear and thorough information and adequate time was allowed to respond to participants' questions. The participants had one session of counselling. However, there were reinforcements of the counselling through reminders to the participants every two weeks for a period of 12 weeks after phase 1. This was achieved with phone calls and short message services (SMS).

Phase 2 commenced 12 weeks after phase 1 and this phase involved re-administration of the questionnaire to assess lifestyle behavioural changes. The post-intervention data collection was carried out in both the intervention and control groups three months after the intervention.

Three trained research assistants, i.e. a resident doctor, a nurse and a health information officer, were used.

\section{Statistical analysis}

All data collected were analysed, using the Statistical Package for the Social Sciences (SPSS) for Windows software version 17.0 (SPSS Inc, Chicago IL, USA). Two-stage analysis was done, involving analysis of the pre-intervention and post-intervention questionnaire. Frequency tables were generated for relevant variables. Means, standard deviations and percentages were determined as appropriate. The means and standard deviation (SD) were calculated for continuous variables while categorical variables were analysed using proportions. A chi-square test was used to determine the statistical significance of observed differences in crosstabulated variables. A test of significance was done using Student's t-test. This t-test was used to compare the means when there were only two means to compare. A $p$-value of $\leq 0.05$ was taken to be statistically significant.

\section{Results}

The mean age (SD) of the respondents was $60.9 \pm 10.2$; the age group 50-59 had the highest numbers of respondents (34.2\%). The majority $(82.9 \%)$ of the respondents were Christians. The sociodemographic characteristics of the respondents (both intervention and control group) were similar, as there is no statistically significant difference between the two groups (Table 1). Table 2 shows that $8.7 \%$ of respondents in the intervention group and $6.2 \%$ of respondents in the control group met the recommendation for physical activity, and $91.3 \%$ of the respondents in the intervention group and $85.7 \%$ of respondents in the control group met the recommendation for alcohol consumption. With regard to smoking, $72.7 \%$ of respondents in the intervention group and $78.3 \%$ of respondents in the control group met the recommendation for smoking. However, the difference in each category of the lifestyle behaviours was not statistically significant $(p=0.396,0.116,0.244)$.

Table 1: Sociodemographic comparison of characteristics of respondents.

\begin{tabular}{|c|c|c|c|c|c|}
\hline Variables & $\begin{array}{l}\text { Intervention group } \\
\qquad(n=161)\end{array}$ & $\begin{array}{l}\text { Control group } \\
(n=161)\end{array}$ & $x^{2}$ & df & $p$-value \\
\hline \multicolumn{6}{|l|}{ Age summary: } \\
\hline Mean $\pm S D^{*}$ & $61.3 \pm 9.7$ & $60.5 \pm 10.3$ & 0.715 & 320 & 0.475 \\
\hline Age in years: & $n(\%)$ & $n(\%)$ & & & \\
\hline $40-49$ & $18(11.2)$ & $24(14.9)$ & 1.570 & 3 & 0.666 \\
\hline $50-59$ & $58(36.0)$ & $52(32.3)$ & & & \\
\hline $60-69$ & $51(31.7)$ & $47(29.2)$ & & & \\
\hline $70+$ & $34(21.1)$ & $38(23.6)$ & & & \\
\hline \multicolumn{6}{|l|}{ Sex: } \\
\hline Male & $76(47.2)$ & 83 (51.6) & 0.609 & 1 & 0.435 \\
\hline Female & $85(52.8)$ & $78(48.4)$ & & & \\
\hline \multicolumn{6}{|l|}{ Marital status: } \\
\hline Single & $4(2.5)$ & $1(0.6)$ & & & $0.197^{* *}$ \\
\hline Married & $128(79.5)$ & 141 (87.6) & & & \\
\hline Divorced & $12(7.4)$ & $9(5.6)$ & & & \\
\hline Widowed & $17(10.6)$ & $10(6.2)$ & & & \\
\hline \multicolumn{6}{|l|}{ Religion: } \\
\hline Christianity & 131 (81.4) & $136(84.5)$ & & & $0.347^{* *}$ \\
\hline Islam & 24 (14.9) & $23(14.3)$ & & & \\
\hline Traditional & $6(3.7)$ & $2(1.2)$ & & & \\
\hline \multicolumn{6}{|l|}{ Ethnicity: } \\
\hline Yoruba & $140(87.0)$ & $146(90.7)$ & & & $0.295^{* *}$ \\
\hline Ibo & $13(8.0)$ & $12(7.4)$ & & & \\
\hline Hausa & $8(5.0)$ & $3(1.9)$ & & & \\
\hline
\end{tabular}

*Independent samples t-test applied. **Fisher's exact test applied. 
Table 2: Pattern of lifestyle behaviours of respondents pre-intervention

\begin{tabular}{|c|c|c|c|c|c|}
\hline Variables & $\begin{array}{l}\text { Intervention group } \\
\qquad(n=161)\end{array}$ & $\begin{array}{l}\text { Control group } \\
(n=161)\end{array}$ & $x^{2}$ & df & $p$-value \\
\hline \multicolumn{6}{|l|}{ Physical activity status: } \\
\hline Met recommendation & $14(8.7)$ & $10(6.2)$ & 0.720 & 1 & 0.396 \\
\hline Did not meet recommendation & $147(91.3)$ & $151(93.8)$ & & & \\
\hline \multicolumn{6}{|l|}{ Fruit and vegetable consumption } \\
\hline Met recommendation & $54(33.5)$ & $65(40.4)$ & 1.613 & 1 & 0.204 \\
\hline Did not meet recommendation & $107(66.5)$ & $96(59.6)$ & & & \\
\hline \multicolumn{6}{|l|}{ Smoking status } \\
\hline Met recommendation & $117(72.7)$ & $126(78.3)$ & 1.359 & 1 & 0.244 \\
\hline Did not meet recommendation & $44(27.3)$ & $35(21.7)$ & & & \\
\hline \multicolumn{6}{|l|}{ Alcohol consumption } \\
\hline Met recommendation & $147(91.3)$ & $138(85.7)$ & 2.473 & 1 & 0.116 \\
\hline Did not meet recommendation & $14(8.7)$ & $23(14.3)$ & & & \\
\hline
\end{tabular}

Table 3: Pattern of lifestyle behaviours of respondents post-intervention

\begin{tabular}{|c|c|c|c|c|c|}
\hline Variables & $\begin{array}{l}\text { Intervention group } \\
\qquad(n=161)\end{array}$ & $\begin{array}{l}\text { Control group } \\
(n=161)\end{array}$ & $x^{2}$ & df & $p$-value \\
\hline \multicolumn{6}{|l|}{ Physical activity: } \\
\hline Met recommendation & $36(22.4)$ & $10(6.2)$ & 17.145 & 1 & 0.000 \\
\hline Did not meet recommendation & $125(77.6)$ & $151(93.8)$ & & & \\
\hline \multicolumn{6}{|l|}{ Fruit and vegetable consumption: } \\
\hline Met recommendation & $115(71.4)$ & $66(41.0)$ & 30.294 & 1 & 0.000 \\
\hline Did not meet recommendation & $46(28.6)$ & $95(59.0)$ & & & \\
\hline \multicolumn{6}{|l|}{ Smoking: } \\
\hline Met recommendation & $135(83.9)$ & $128(78.5)$ & 1.017 & 1 & 0.313 \\
\hline Did not meet recommendation & $26(16.1)$ & $33(20.5)$ & & & \\
\hline \multicolumn{6}{|l|}{ Alcohol consumption: } \\
\hline Met recommendation & $161(100.0)$ & $141(87.6)$ & 21.325 & 1 & 0000 \\
\hline Did not meet recommendation & $0(0.0)$ & $20(12.4)$ & & & \\
\hline
\end{tabular}

Table 3 shows that many respondents in the intervention group met the recommendations for physical activity (22.4\%), fruit and vegetable consumption (71.4\%) and alcohol consumption (100\%) compared with the control group $(6.2 \%, 41.0 \%, 87.6 \%)$ post-intervention. The difference in each category was statistically significant $(p<0.001)$. However, the difference in smoking habits between the two groups ( $83.9 \%$ vs. $79.5 \%$ ) was not statistically significant $(p=0.313)$. There was no statistically significant difference $(p=0.268)$ in MAP of the intervention and control group pre-intervention; however, there was a statistically significant difference ( $p$ $<0.001)$ in MAP $(96.4 \pm 8.1$ vs $106.2 \pm 7.6 \mathrm{mmHg})$ between the intervention and control group post-intervention (Table 4).

\section{Discussion}

In this study at baseline, the pattern of lifestyle behaviour with regard to physical exercise was $8.7 \%$ in the intervention group and $6.2 \%$ in the control group. These were lower than $16.4 \%$, $31 \%$ and $38.9 \%$ as found in similar studies in Nigeria, Turkey and the USA respectively ${ }^{11,15}$ The differences in the methodology and location of the studies may account for observed differences. However, the lower uptake of physical activity in this study might be due to the fact that many participants engaged in sedentary jobs (e.g. teaching, clerk). Also, reliance on labour-saving devices and use of automobiles instead of walking/cycling to work may be responsible for low daily physical exercise. The pattern of lifestyle behaviour with regard to fruit and vegetable consumption in this study was lower than $75.7 \%$ (dietary vegetables) and $66.2 \%$ (dietary fruits) as found in a similar study in Nigeria, ${ }^{15}$ but higher than $12.9 \%$ and $25.2 \%$ as found in another Nigeria and USA study respectively. ${ }^{4,11}$ The consumption of fruits and vegetables among the study population might be influenced by the agricultural

Table 4: Summary of change in mean arterial blood pressure of respondents

\begin{tabular}{|c|c|c|c|c|c|}
\hline Variables & $\begin{array}{l}\text { Intervention group } \\
\quad(n=161)\end{array}$ & $\begin{array}{l}\text { Control group } \\
(n=161)\end{array}$ & $t$-test & df & $p$-value \\
\hline \multicolumn{6}{|l|}{ Pre-intervention: } \\
\hline Mean arterial pressure $(\mathrm{mmHg})$ & $105.9 \pm 8.4$ & $106.9 \pm 8.3$ & -1.108 & 320 & 0.268 \\
\hline \multicolumn{6}{|l|}{ Post-intervention: } \\
\hline Mean arterial pressure $(\mathrm{mmHg})$ & $96.4 \pm 8.1$ & $106.2 \pm 7.6$ & -11.232 & 320 & $<0.001$ \\
\hline
\end{tabular}


endowment of the Ekiti people, as most people have farms/ gardens irrespective of their status in the society and as such there is availability and affordability of fresh fruits and vegetables. The pattern of lifestyle behaviour with regard to tobacco smoking was higher than $6.5 \%, 8 \%$ and $12 \%$ as reported in Nigeria, Accra and India. 4,16,17 The differences in study population, study design and geographical location might account for the differences in smoking/tobacco usage. Also, the high proportion of tobacco users (smokers) may be due to inclusion of tobacco and snuff use in this study. The pattern of lifestyle behaviour with regard to alcohol in this study was similar to the $90.7 \%$ found in a descriptive cross-sectional study carried out on adult patients with essential hypertension at a primary care clinic in Nigeria, ${ }^{15}$ but higher than $32.3 \%$ as found in a descriptive cross-sectional study carried out among hypertensive adults in a semi-urban community in Nigeria. ${ }^{4} \mathrm{~A}$ high percentage of respondents meeting alcohol consumption and tobacco smoking recommendations may be connected to their religious inclinations, which discourage smoking and alcohol consumption.

It was found in this study that the difference between lifestyle behaviours of the intervention and control group was not significant before the intervention but counselling intervention improved lifestyle behaviours in the intervention group. Postintervention result showed that $36(22.4 \%)$ and $10(6.2 \%)$ of the intervention and the control group met the recommendation for physical exercise, 115 (71.4\%) of the intervention group and $66(41.0 \%)$ of the control group met the recommendation for fruit and vegetable consumption, while 161 (100.0) of the intervention group and 141(87.6) of the control group met the recommendation for alcohol. The differences in each lifestyle were statistically significant, $p<0.001$. However, post-intervention the difference in the smoking pattern in the intervention and control group was not statistically significant, $p=0.313$. This might be due to the addictive nature of smoking and the age group of the study population. The findings in this study were similar to Bjorkna's study in a randomised trial of lifestyle intervention in primary healthcare, ${ }^{18}$ especially on physical activity and tobacco use. In that study, counselling intervention led to improved lifestyle behaviour among the intervention group in all the domains, and the differences were statistically significant, $p<0.001$. In a study among market women in Lagos, the proportion of hypertensive subjects who commenced medication and lifestyle modification post-counselling increased from $30.2 \%$ to $97.67 \% .{ }^{19}$ Physicians counselling on lifestyle during their encounters with adult hypertensive patients remain imperative for optimum care, and receiving counselling from a physician regarding a healthy lifestyle led to maintenance of a healthy lifestyle. ${ }^{20}$

In the present study, in the intervention group only $22.4 \%$ met recommendations for physical activity and $100 \%$ met recommendations for alcohol consumption post-intervention. This finding is in agreement with the reports that physical activity is inadequate among hypertensive individuals in Nigeria and Kuwait. ${ }^{3,21}$ This may mean that cultural and geographical differences have little or no influence on adoption of physical activity as a lifestyle. Technological advancement in terms of transport, which had replaced trekking, cycling and horse riding, and less involvement in manual agriculture in Nigeria may be partly responsible.

The pre-intervention MAP was $105.9 \pm 8.4$ and $106.9 \pm 8.3$ $\mathrm{mmHg}$ for the intervention and control group respectively while the MAP post-intervention was $96.4 \pm 8.1$ and $106.2 \pm 7.6$ $\mathrm{mmHg}$ in the intervention and control group respectively, and the difference is statistically significant. Ultimately, this shows that lifestyle counselling and behavioural change among the intervention group may be the probable reason for achieving better blood pressure control, as reflected in the MAP.

\section{Conclusion}

Lifestyle behavioural counselling intervention and reminders among the intervention group of hypertensive patients had a positive impact on lifestyle behaviour and ultimately resulted in better blood pressure control. Counselling hypertensive patients on physical activity and the consequences of inactivity should be the most important aspect of hypertensive management in primary care. Physicians need to maintain constant counselling in a patient-centred manner to achieve improved lifestyle in hypertensive individuals.

\section{Limitations}

This study only matched for sociodemographic characteristics, but not for other variables such as therapy-related factors (medication cost, complexity of regimen). Also, the intervention was short due to time constraints. Hence, longer duration research to determine the effect of lifestyle counselling on blood pressure control is recommended.

Acknowledgement - The help of all resident doctors in the department of Family Medicine, Federal Medical Centre, IdoEkiti is greatly appreciated.

Disclosure statement - No potential conflict of interest was reported by the authors.

Financial support and sponsorship - None.

\section{References}

1. Akpa MR, Alasia DD, Emem-Chioma PC. An appraisal of hospital based blood pressure control in Port Harcourt, Nigeria. The Nigerian Health Journal. 2008;8(1-2):27-30.

2. Ghezelbash S, Ghorbani A. Lifestyle modification and hypertension prevention. ARYA Atherosclerosis Journal. 2012;8:202-7.

3. Katibi IA, Olarinoye JK, Kuranga SA. Knowledge and practice of hypertensive patients as seen in a tertiary hospital in the middle belt of Nigeria. Niger J Clin Pract. 2010;13(2):159-62.

4. Okwuonu CG, Emmanuel Cl, Ojimadu NE. Perception and practice of lifestyle modification in the management of hypertension among hypertensives in south-east Nigeria. Int J Med Biomed Res. 2014;3 (2):121-31. https://doi.org/10.14194/ijmbr.3.2.8

5. Chobanian AU, Bakris GL, Black HR, et al. Seventh report of the joint national committee on prevention, detection, evaluation and treatment of high blood pressure. JAMA. 2003;289:2560-72. https://doi. org/10.1001/jama.289.19.2560

6. Weber MA, Schiffrin EL, White WB, et al. Clinical practice guidelines for the management of hypertension in the community: a statement by the American society of hypertension and the international society of hypertension. J Hypertens. 2014;32:3-15. https://doi.org/ 10.1097/HJH.0000000000000065

7. Ghezelbash $S$, Ghorbani A. Lifestyle modification and hypertension prevention. ARYA Atherosclerosis J. 2012;8:202-7.

8. Clinical practice guidelines, management of hypertension. 2008 [cited 2014 Nov 3] Available from www.moh.gov.my.

9. Bramlage $P$, Pittrow $D$, Wittchen $H$, et al. Hypertension in overweight and obese primary care patients is highly prevalent and poorly controlled. AJH. 2004;17(10):904-10.

10. WHO. The WHO STEPSwise approach to chronic disease risk factor surveillance (STEPS). [cited 2014 Nov 19]. Available from www.who. int/chp/steps. 
11. Zhao G, Ford ES, Mokdad AH. Racial/ethnic variation in hypertension related lifestyle behaviours among US women with self-reported hypertension. J Hum Hypertens. 2008;22:608-16. https://doi.org/10. 1038/jhh.2008.52

12. The British Dietetic Association. Food fact sheet 2011. [cited 2014 Oct 2]. Available from www.bda.uk.com/foodfacts.

13. Smith SC, Benjamin EJ, Bonow RO, et al. AHA/ACCF secondary prevention and risk reduction therapy for patients with coronary and other atherosclerotic vascular disease: 2011 update. J Am Coll Cardiol. 2011;58(23):2432-46. https://doi.org/10.1016/j.jacc.2011.10.824

14. Searight HR. Realistic approach to counselling in the office setting. Am Fam Physician. 2009;79(4):277-84.

15. Iloh GUP, Amadi AN, Okafor GOC, et al. Adherence to lifestyle modifications among adult hypertensive Nigerians with essential hypertension in a primary care clinic of a tertiary hospital in resourcepoor environment of eastern Nigeria. Br J Med Med Res. 2014;4 (18):3478-90. https://doi.org/10.9734/BJMMR/2014/9439

16. Marfo AFA, Owusu-Daaku FT, Addo MO, et al. Ghanaian hypertensive patients understanding of their medicines and life style modification for managing hypertension. Int J Pharm Pharm Sci. 2014;6(4):165-70.
17. Manimunda PS, Sugunan PA, Benegal V, et al. Association of hypertension with risk factors and hypertension related behaviour among the aboriginal Nicobarese tribe living in Car Nicobar Island, India. Indian J Med Res. 2011;133:287-93.

18. Eriksson KM, Westborg CJ, Eliasson CE. A randomised trial of lifestyle intervention in primary healthcare for the modification of cardiovascular risk factor. The Bjoknas study. Scand J Public Health. 2006;34:453-61. https://doi.org/10.1080/14034940500489826

19. Onwuchekwa AC, Mezie-Okoye MM, Babatunde S. Prevalence of hypertension in Kegbara-Dere, a rural community in the Niger Delta Region, Nigeria. Ethn Dis. 2012;22(3):340-6.

20. Heymann AD, Gross $R$, Tabenkin $H$, et al. Factors associated with hypertensive patients' compliance with recommended lifestyle behaviours. IMAJ. 2011;13:553-7.

21. Serour M, Alqhenaei H, Al-Saqabi $\mathrm{S}$, et al. Cultural factors and patients' adherence to lifestyle measures. British Journal of General Practice. 2007;57:291-5.

Received: 20-09-2018 Accepted: 5-01-2019 